all patients with a DNAH11 defect $(\mathrm{n}=5)$ compared to healthy controls $(n=3)$ and patients with PCD due to a defect of the central pair or nexin link $(\mathrm{n}=3)$ (Figure 1). A reduction in outer dynein arm volume of $30 \%$ was identified compared to healthy and PCD controls.

In conclusion, a mutation in DNAH11 results in a subtle abnormality in ultrastructure. The defects are specific to the 'forearm' of the outer dynein arm and only detectable at the base of the cilium where DNAH11 is located. Electron tomography is highly effective in visualising this defect.

\section{S89 IDENTIFICATION OF POTENTIALLY PATHOGENIC MICROORGANISMS BY SELECTED ION FLOW TUBE - MASS SPECTROMETRY (SIFT-MS)}

${ }^{1} \mathrm{JM}$ Jackson, ${ }^{2} \mathrm{VL}$ Kim, ${ }^{3} \mathrm{AC}$ Tuck, ${ }^{1} \mathrm{SA}$ Wootton, ${ }^{4} \mathrm{TM}$ Wilkinson. ${ }^{1} \mathrm{NIHR}$ Southampton Biomedical Research Centre, Southampton, UK; ${ }^{2}$ NIHR Southampton Respiratory Biomedical Research Unit, Southampton, UK; ${ }^{3}$ Infectious Disease Epidemiology Group, Sir Henry Wellcome Laboratories, Academic Unit of Clinical and experimental Sciences, Faculty of Medicine, University of Southampton, Southampton, UK; ${ }^{4}$ University Hospital Southampton NHS Foundation Trust, Southampton, UK

\subsection{6/thoraxjn-2014-206260.95}

Introduction Improved targeted therapy and reduced clinical burden from respiratory bacterial infection could result from early identification of specific Potential Pathogenic Microorganisms (PPM). Sputum culture for identification usually requires several days. SIFT-MS has the potential to reduce the required incubation time by sampling the culture headspace to generate an ionic spectrum from volatile organic compounds that may be characteristic of the PPM. Additionally, these signatures may be detectable in breath taken directly from patients. This pilot study investigates the potential of SIFT-MS to identify 5PPMs, incubated separately for $24 \mathrm{hr}$.

Methods Training set: Haemophilus influenzae (HI), Moraxella catarrhalis (MC), Streptococcus pneumoniae (SP), Staphylococcus aureus (SA) and Pseudomonas aeruginosa (PA) cultures and a negative control incubated at $37^{\circ} \mathrm{C}$ on chocolate agar plates in sealed bags for $24 \mathrm{hr}, 48 \mathrm{hr}$ and $72 \mathrm{hr}$. Plates were opened for $10 \mathrm{~min}$ at room temperature before ionic spectra of the gas above the culture dishes in the range 15 to 200 mass units were recorded using SIFT-MS and standardised to operating conditions. Test set: the same five PPMs and a negative control were incubated in triplicate for $24 \mathrm{hr}$ only and analysed as above.

Results Using the spectra generated with $\mathrm{H} 3 \mathrm{O}+$ ionisation, 6 ion sets were identified. The sum of ions within each set, expressed as a percentage of the total ion sum of masses 15 to 200 (excluding reagent ions) fell into ranges that, in combination, differentiated between the PPMs. This set of conditions was incorporated into an algorithm that was then applied to the test set of triplicate plates. The algorithm correctly differentiated all $24 \mathrm{hr}$ plates with MC, SP, SA and PA from each other and from the negative control and HI plates with 100\% accuracy. Negative control and HI could not be differentiated.

Conclusion This pilot study illustrates the potential for SIFT-MS to identify monocultures of 4 common PPMs within a short incubation time and encourages further study with a wider range of pathogens alone and in combination. Early identification of PPMs in culture, and translation to potentially detect carriage or infection with specific pathogens in breath may improve management of respiratory infections.
S90 ROLE FOR IL-1ALPHA IN VIRAL-INDUCED INFLAMMATORY RESPONSES IN A CO-CULTURE MODEL OF THE AIRWAY MUCOSA

${ }^{1} \mathrm{~A}$ Hill, ${ }^{1} \mathrm{~L}$ Tezera, ${ }^{1} \mathrm{C}$ Blume, ${ }^{2} \mathrm{C}$ Grainge, ${ }^{1} \mathrm{DE}$ Davies, ${ }^{1} \mathrm{EJ}$ Swindle. ${ }^{1}$ University of Southampton (Clinical and Experimental Sciences, Faculty of Medicine), Southampton, UK;

${ }^{2}$ University of Newcastle (School of Medicine and Public Health), Newcastle, Australia

10.1136/thoraxjil-2014-206260.96

Introduction Asthma is an inflammatory disease of the conducting airways which is exacerbated by environmental exposures, such as viral infections. Bronchial epithelial cells (BECs) together with underlying fibroblasts form an epithelial mesenchymal trophic unit (EMTU) that maintains normal tissue homeostasis. In asthma the EMTU is dysregulated. Recent evidence suggests that viral infections activate the epithelial barrier resulting in mediator release which could potentially activate fibroblasts. Therefore, we hypothesised that exposure to viruses activates inflammatory and anti-viral responses in the EMTU.

Methods The EMTU was modelled using a co-culture system of polarised BECs (16HBE14o-) and fibroblasts (MRC5s) maintained on the apical and basolateral surface of a nanoporous membrane respectively. After 6 days the model was challenged apically with poly (I:C) (a viral mimetic) and barrier responses were determined by measuring transepithelial resistance (TER) while cytokine release was determined by ELISA.

Results Following poly (I:C) stimulation a significant reduction in TER was observed in both the EMTU model and BEC monocultures. However, the EMTU model maintained a higher TER at 6-24 h after challenge. With regards to cytokine secretion, poly (I:C) stimulation significantly induced pro-inflammatory (IL-6, IL-8, GM-CSF and IL-1 $\alpha$ ) and anti-viral (IP-10) mediator release from BEC but not fibroblast monocultures. In the EMTU model, basolateral IL-6, IL-8, GM-CSF and IP-10 responses to poly (I:C) were significantly enhanced compared to BEC monocultures. In addition, basolateral pro-inflammatory (IL-6, IL-8 and GM-CSF) but not antiviral (IP-10) responses to poly (I:C) were abrogated in the EMTU model after pre-incubation with IL-1 receptor antagonist (IL-1ra). Furthermore, direct stimulation with IL- $1 \alpha$ induced IL- 6 and IL- 8 release in the EMTU model and fibroblast monocultures but not in BEC monocultures.

Conclusions Poly (I:C) activates inflammatory and anti-viral responses in BEC monocultures and fibroblast co-culture models of the EMTU. These responses were enhanced in the co-culture model suggesting that the EMTU is activated. Inflammatory but not anti-viral responses were mediated by epithelial-derived IL$1 \alpha$ acting on the underlying fibroblasts. This may have important consequences in promotion of inflammation and airway remodelling in viral-induced exacerbations of asthma.

\section{New asthma treatments}

\section{S91 ONCE-DAILY TIOTROPIUM RESPIMAT® ADD-ON TO ICS + LABA IMPROVES SYMPTOM CONTROL AND REDUCES EXACERBATIONS IN PATIENTS WITH SYMPTOMATIC ASTHMA}

${ }^{1} \mathrm{D}$ Price, ${ }^{2} \mathrm{M}$ Engel, ${ }^{2} \mathrm{P}$ Moroni-Zentgraf, ${ }^{2} \mathrm{H}$ Schmidt, ${ }^{3} \mathrm{R}$ Dahl, ${ }^{4} \mathrm{P}$ Paggiaro, ${ }^{5} \mathrm{M}$ Vandewalker, ${ }^{6}$ HAM Kerstiens, ${ }^{7}$ A Kaplan. ${ }^{1}$ Institute of Applied Health Sciences, University of Aberdeen, Aberdeen, UK; ${ }^{2}$ Boehringer Ingelheim Pharma GmbH and Co. KG, Biberach an Der Riss, Germany; ${ }^{3}$ Odense University Hospital, Odense, Denmark; ${ }^{4}$ University of Pisa, Pisa, Italy; ${ }^{5}$ Clinical Research of the Ozarks, Colombia, USA; ${ }^{6}$ University Medical Center Groningen, Groningen, The Netherlands; ${ }^{7}$ Family Physician Airways Group of Canada, Ontaria, Canada

10.1136/thoraxjnl-2014-206260.97 
Background We evaluated the effect of once-daily tiotropium Respimat ${ }^{\circledR} 5 \mu \mathrm{g}$ on lung function, asthma exacerbation and asthma symptom control among patients with symptomatic asthma receiving inhaled corticosteroids (ICS; $\geq 800 \mu \mathrm{g} /$ day budesonide or equivalent) + long-acting $\beta_{2}$-agonist (LABA).

Methods Data were pooled from two replicate, double-blind, placebo-controlled, 48-week, parallel-group studies of once-daily tiotropium $5 \mu \mathrm{g}$ versus placebo, both delivered via the Respimat $^{\circledR}$ SoftMist ${ }^{\mathrm{TM}}$ inhaler (PrimoTinA-asthma ${ }^{\circledR}$ : NCT00772538, NCT00776984). Eligible patients had: $\geq 5$-year history of asthma diagnosed before the age of 40 years; seven-question Asthma Control Questionnaire (ACQ-7) score of $\geq 1.5$; experienced $\geq 1$ exacerbation during the previous year. Patients were either lifelong non-smokers, or ex-smokers ( $<10$ pack-years) who quit smoking $\geq 1$ year before study enrolment. Exclusion criteria included diagnosis of chronic obstructive pulmonary disease. Coprimary end points in individual trials: peak forced expiratory volume in 1 second $\left(\mathrm{FEV}_{1}\right)$ within $3 \mathrm{~h}$ post-dose $(0-3 \mathrm{~h})$ and trough $\mathrm{FEV}_{1}$. A co-primary end point in pooled data was time to first severe exacerbation; secondary end points included time to first episode of asthma worsening and ACQ-7 response. Post hoc efficacy analyses were performed.

Results 912 patients were randomised to receive tiotropium Respimat $^{\circledR}(n=456)$ or placebo Respimat ${ }^{\circledR}(n=456)$. At Week 48, tiotropium Respimat ${ }^{\circledR}$ was associated with statistically significant improvements versus placebo Respimat ${ }^{\circledR}$ in peak $\mathrm{FEV}_{1(0-3 \mathrm{~h})}$ (adjusted mean difference $100 \mathrm{~mL}$; 95\% confidence interval: 52, $148 ; \mathrm{p}<0.0001$ ) and trough $\mathrm{FEV}_{1}$ (adjusted mean difference 62 $\mathrm{mL} ; 95 \%$ confidence interval: 18,$106 ; \mathrm{p}=0.006$ ). Time to first severe asthma exacerbation was significantly longer with tiotropium Respimat ${ }^{\circledR}$ versus placebo Respimat ${ }^{\circledR}$ (282 vs 226 days, respectively; hazard ratio $0.79 ; \mathrm{p}=0.034)$, as was time to first episode of asthma worsening (315 vs 181 days, respectively; hazard ratio $0.69 ; \mathrm{p}<0.0001)$. At Week 24, ACQ-7 responder rate was significantly higher with tiotropium Respimat ${ }^{\circledR}$ (53.9\%) versus placebo Respimat ${ }^{\circledR}$ (46.9\%; odds ratio 1.32; $\left.\mathrm{p}=0.0427\right)$. Conclusion Once-daily tiotropium Respimat ${ }^{\circledR}$ add-on to ICS + LABA improves lung function, reduces risk of severe asthma exacerbation and asthma worsening, and significantly improves asthma symptom control compared with placebo Respimat ${ }^{\circledR}$ in patients with symptomatic asthma.

\section{S92 EFFICACY OF ONCE-DAILY TIOTROPIUM RESPIMAT® 5 $\mu G$ FROM FIVE PHASE III TRIALS IN ADULTS WITH SYMPTOMATIC ASTHMA}

${ }^{1} \mathrm{D}$ Price, ${ }^{2} \mathrm{ED}$ Bateman, ${ }^{3} \mathrm{P}$ Paggiaro, ${ }^{4} \mathrm{~A}$ Kaplan, ${ }^{5} \mathrm{M}$ Engel, ${ }^{5} \mathrm{H}$ Schmidt, ${ }^{5} \mathrm{P}$ Moroni-Zentgraf, ${ }^{6}$ HAM Kerstjens. ${ }^{1}$ Institute of Applied Health Sciences, University of Aberdeen, Aberdeen, UK; ${ }^{2}$ University of Cape Town, Cape Town, South Africa; ${ }^{3}$ University of Pisa, Pisa, Italy; ${ }^{4}$ Family Physician Airways Group of Canada, Ontaria, Canada; ${ }^{5}$ Boehringer Ingelheim Pharma GmbH and Co. KG, Biberach an Der Riss, Germany; ${ }^{6}$ University Medical Center Groningen, Groningen, The Netherlands

\subsection{6/thoraxjnl-2014-206260.98}

Background Recent clinical trials have indicated that the longacting antimuscarinic agent tiotropium, a once-daily long-acting bronchodilator, may provide benefit to patients with symptomatic asthma. We investigated primary efficacy data (lung function, risk of severe exacerbation and seven-question Asthma Control Questionnaire [ACQ-7] response) from five Phase III, randomised, double-blind, parallel-group trials that evaluated the efficacy and safety of once-daily tiotropium add-on versus placebo add-on (all tiotropium doses delivered via the Respimat ${ }^{\circledR}$

\begin{tabular}{|c|c|c|c|}
\hline & \multicolumn{3}{|c|}{ Adjusted mean of difference in response from placebo $(\mathrm{mL})$} \\
\hline & $\begin{array}{l}\text { PrimoTinA-asthma } \\
\text { (Week 24) }\end{array}$ & $\begin{array}{l}\text { MezzoTinA-asthma }{ }^{\circledR} \\
\text { (Week 24) }\end{array}$ & $\begin{array}{l}\text { GraziaTinA-asthma }{ }^{\circledR} \\
\text { (Week 12) }\end{array}$ \\
\hline & $\begin{array}{l}\text { Tiotropium } \\
\text { Respimat }^{\circledR} 5 \mu \mathrm{g}^{\mathrm{a}} \\
(\mathrm{n}=456)\end{array}$ & $\begin{array}{l}\text { Tiotropium } \\
\text { Respimat }^{\circledR} 5 \mu \mathrm{g}^{\mathrm{a}} \\
(\mathrm{n}=517)\end{array}$ & $\begin{array}{l}\text { Tiotropium } \\
\text { Respimat }^{\circledR} 5 \mu \mathrm{g} \\
(\mathrm{n}=155)\end{array}$ \\
\hline Peak FEV ${ }_{1(0-3 h)}$ & $110(p<0.0001)$ & $185(p<0.0001)$ & $128(p=0.0005)$ \\
\hline Trough FEV ${ }_{1}$ & $93(p=0.0058)$ & $146(p<0.0001)$ & $122(p=0.0010)$ \\
\hline $\mathrm{FEV}_{1} \mathrm{AUC}_{(0-3 \mathrm{~h})}$ & $107(p<0.0001)$ & $182(p<0.0001)$ & $125(p=0.0003)$ \\
\hline Peak $\mathrm{FVC}_{(0-3 h)}$ & $87(p=0.0050)$ & $95(p<0.0001)$ & $57(p=0.1714)$ \\
\hline \multicolumn{4}{|c|}{$\begin{array}{l}\text { aPooled data } \\
\text { AUC, area under the curve; } \text { FEV }_{1} \text {, forced expiratory volume in } 1 \text { second; FVC, forced vital } \\
\text { capacity }\end{array}$} \\
\hline
\end{tabular}

SoftMist $^{\mathrm{TM}}$ inhaler) in adults with symptomatic asthma on inhaled corticosteroid (ICS) \pm long-acting $\beta_{2}$-agonist (LABA) maintenance therapy.

Methods Two 48-week trials of tiotropium Respimat ${ }^{\circledR} 5 \mu \mathrm{g}$ (PrimoTinA-asthma ${ }^{\circledR}:$ NCT00776984, NCT00772538) in patients on high-dose ICS ( $\geq 800 \mu \mathrm{g}$ budesonide or equivalent) + LABA; two 24-week trials of tiotropium Respimat ${ }^{\circledR} 5 \mu \mathrm{g}$ and $2.5 \mu \mathrm{g}$ (MezzoTinA-asthma ${ }^{\circledR}$ : NCT01172808, NCT01172821) in patients on moderate-dose ICS (400-800 $\mu \mathrm{g}$ budesonide or equivalent); one 12-week trial of tiotropium Respimat ${ }^{\circledR} 5 \mu \mathrm{g}$ and $2.5 \mu \mathrm{g}$ (GraziaTinA-asthma ${ }^{\circledR}$ : NCT01316380) in patients on low-dose ICS (200-400 $\mu$ g budesonide or equivalent).

Results 3476 patients were treated, of whom 1128 received tiotropium Respimat ${ }^{\circledR} 5 \mu \mathrm{g}$. Once-daily tiotropium Respimat ${ }^{\circledR} 5 \mu \mathrm{g}$ significantly improved lung function (Table) in patients with not fully controlled asthma receiving low- to high-dose ICS. In addition, tiotropium Respimat ${ }^{\circledR} 5 \mu \mathrm{g}$ reduced the risk of severe exacerbations versus placebo (co-primary end point) in patients on high-dose ICS + LABA (hazard ratio 0.79; p = 0.0343), and there was an increase in ACQ-7 responder rate (co-primary end point) with the $5 \mu \mathrm{g}$ dose (odds ratio $1.32 ; \mathrm{p}=0.0308$ ) compared with placebo in patients on moderate-dose ICS.

Conclusion Once-daily tiotropium Respimat ${ }^{\circledR}$ significantly improves lung function in adult patients with symptomatic asthma receiving a range of doses of ICS, including even highdose ICS + LABA, suggesting a potential role for this treatment as add-on to ICS in adults with symptomatic asthma.

\section{S93 A PROSPECTIVE STUDY INVESTIGATING EXACERBATIONS, HEALTHCARE UTILISATION AND HEALTH ECONOMIC INDICATORS IN OMALIZUMAB TREATED SEVERE ALLERGIC ASTHMA PATIENTS - RESULTS FROM AN INTERIM ANALYSIS OF THE APEX II STUDY}

${ }^{1} \mathrm{M}$ Masoli, ${ }^{2} \mathrm{~A}$ Menzies-Gow, ${ }^{3} \mathrm{~L}$ Dobson, ${ }^{4} \mathrm{JB}$ Moriaria, ${ }^{5} \mathrm{R}$ Allcock, ${ }^{6} \mathrm{R}$ Niven. ${ }^{1}$ Derriford Hospital, Derriford, UK; ${ }^{2}$ Royal Brompton Hospital, London, UK; ${ }^{3}$ Torbay Hospital, Torbay, UK; ${ }^{4}$ Hull Royal Infirmary, Hull, UK; ${ }^{5}$ Queen Elizabeth Hospital Gateshead, Gateshead, UK; ${ }^{6}$ University Hospital of South Manchester, Manchester, UK

\subsection{6/thoraxjn-2014-206260.99}

Background A previous retrospective study of UK clinical practice demonstrated that omalizumab was associated with reduced exacerbations and healthcare utilisation in severe allergic asthmatics. 